\title{
Reseña sobre el libro "La anti-productividad. Así como estamos funcionando no está funcionando"
}

\author{
Review on the book "The way we're working isn't working”
}

Brenda Elizalde-Rivera $^{a}$

\begin{abstract}
:
In the book "The way we're working isn't working” Schwartz, Gomes y McCarthy describe how the proper implementation of a work motivation system in organizations appears as the most innovative contribution to obtain high-performance results.

Keywords:

Motivation, high-performance, innovation

Resumen:

En el libro "La anti-productividad. Así como estamos funcionando no está funcionando" Schwartz, Gomes y McCarthy describen como la adecuada implementación de un sistema de motivación laboral en las organizaciones figura como el aporte más innovador para obtener resultados de alto rendimiento.
\end{abstract}

Palabras Clave:

Motivación, Alto desempeño, Innovación

\section{Introducción}

Los autores plantean cómo el sistema de relación laboral entre empleado-contratante que impera actualmente es deficiente, desgastante y problemático. Las organizaciones siempre tienden a maximizar sus utilidades basándose en el esfuerzo unilateral de sus empleados, y con la recompensa monetaria como método exclusivo en intercambio por el tiempo laborado, la consecuencia inmediata es la frustración, el hastío creciente en el trabajador y el poco o nulo compromiso de los empleados hacia la empresa. Estas constantes negativas inciden sobre los niveles de calidad y producción, pues una relación monovalente de tiempo pagado con dinero es insuficiente para satisfacer las áreas clave necesarias para un trabajo de alto rendimiento en los empleados, priorizar la atención sobre estas áreas y subsanar los errores de compensación sobre ellas provocarían un desempeño superior y un sentido de pertenencia a la empresa sobre los colaboradores exponiendo las mejoras obvias a la actividad económica que realiza la organización.
Dentro del contexto laboral, ninguna interacción es lineal. Las circunstancias problemáticas subyacen en diversos niveles a discernir para una solución satisfactoria a todos los involucrados; sin embargo, el método que impera únicamente contempla el tiempo longitudinal 0 transversal sobre el trabajo para acordar una recompensa adecuada al resultado de esa ecuación, sin duda uno de los daños colaterales a la introducción del sistema automatizado o de producción en cadena que trajo consigo la revolución industrial.

Los humanos no pueden trabajar como lo hacen las máquinas durante largos y constantes ciclos de tiempo con ocasionales y aleatorias pausas de mantenimiento; aunque esa sea la idea generalizada dentro de las empresas, una inminente avalancha de estudios sobre desempeño efectivo disipa toda la niebla ilusoria sobre la sentencia adoptada por muchos "tiempo es dinero". Las personas necesitan equilibrar cuatro áreas básicas: física, emocional, mental y espiritual, y las organizaciones 
deben implementar recursos a disposición de los empleados para armonizar esas áreas y hacer notar que el tiempo trabajado no es la variable por considerar, sino, el valor de producción obtenido durante ese tiempo.

Las motivaciones intrínsecas de los humanos para realizar cualquier actividad, sea placentera o no, han sido poco estudiadas, el panorama es incluso más precario en los ambientes laborales. El axioma de los humanos cerebralmente emocionales es útil para catalogar cómo las decisiones que se toman dentro de una organización están interconectadas con las demás situaciones de los trabajadores, la conciencia de esas relaciones permite discernir entre el autoengaño hacia el desempeño de un empleado, así como la armonía entre los puntos débiles y fuertes. Crear rutinas eficientes es complicado con solo voluntad y disciplina, cambios reales perdurables son más fáciles de lograr con pequeñas modificaciones diarias hasta que se implante una automatización inconsciente, entre más repetitivas y rutinarias sean las acciones, menos energía requerirán.

Es muy común en las organizaciones que los empleados utilicen más energía de la que pueden recuperar en su tiempo libre, y este sesgo se vuelve enorme para trabajos sedentarios. Resulta básico conocer que un adecuado reabastecimiento de energía es imperante para un alto desempeño, pero no solo una exhibición de él, que ese desempeño sea sostenible depende directamente de una renovación energética en periodos de tiempo establecidos. El sueño es la manera directa para recuperar energía, minimizar el impacto de las siestas o el sueño profundo, modifica el desempeño de los trabajadores durante sus jornadas.

Los trabajos sedentarios son casi la antítesis de la actividad física, la cual es una excelente opción para desechar aprehensión y estrés y además proporciona una mejor asimilación del descanso para recobrar energía. Actividades de bajo impacto como caminatas o yoga ligero podrían considerarse ideales para empleados que tienen muy poca actividad durante su jornada laboral, incluso el entrenamiento de resistencia o fuerza puede ser adoptado con un horario adecuado para mejorar notablemente el desempeño en el trabajo.

En un punto de vista completamente tangible la nutrición es protagonista directa de un buen reabastecimiento de energía o de una precaria demostración de habilidades. El alimento es nuestra principal fuente de glucosa, sustancia que el cerebro y el cuerpo necesitan para transformar en energía. Muchos alimentos proporcionan altas cantidades de glucosa, pero son dañinos a largo plazo. Planificar nuestros alimentos en porciones pequeñas pero continuas en lugar de porciones grandes menos frecuentes es más beneficioso para el organismo y más saludable a lo largo del tiempo. Para los alimentos con mucha azúcar resistirse a la tentación de comerlos no es suficiente para controlar su consumo, pues eso agotará nuestra reserva de voluntad, negarse no es el camino, las porciones pequeñas si lo son.

Las organizaciones deben crear políticas, prácticas y servicios que sostengan y alienten a los empleados a comer, dormir y ejercitarse, eso significa un gran cambio de mentalidad laboral en los líderes empresariales, pues ahora las competencias no son el estandarte para usar, sino el completo uso de las habilidades de los trabajadores en sus puestos. También aprender a discernir cuando hay momentos óptimos para realizar tareas más demandantes y cuando es mejor realizar actividades de bajo requerimiento energético pues el estado de ánimo influye considerablemente en el rendimiento, el principal problema radica en la consciencia de cuál es el estado de ánimo que tienen los trabajadores en determinado momento. Existen cuatro zonas para determinar una emoción: zona de rendimiento, zona de supervivencia, zona de renovación y zona de agotamiento. El principal reto para los líderes es movilizar, concentrar y renovar la energía de sus subordinados.

Nuestra necesidad emocional básica es sentirnos seguros, cuando no lo sentimos, consumimos más energía para conservar esa seguridad y destinamos menos para crear valor. Los fracasos son más comunes que las situaciones de éxito, no podemos cambiar los hechos, pero podemos decidir qué hacer con ellos, actuar de manera analítica acerca de cómo respondemos al fracaso nos vuelve más fuertes para reconocer nuestras debilidades además de entender nuestras fortalezas y al aceptar este dúo ya no tenemos que defender nuestro valor y podemos enfocarnos en la información que recibimos para aprender. Los líderes que evitan el conflicto causan más estragos que los que actúan de forma directa. Equilibrar la franqueza y el reconocimiento es la clave para criticar una conducta específica.

La incipiente tendencia de la multitareas afecta negativamente los niveles de atención pues manejar grandes cantidades de información dificulta su priorización, lo que causa un modo reactivo a la distracción y disminuye la eficacia. Contar con una agenda listada de las tareas a realizar y ordenarla de acuerdo con su importancia ayuda a focalizar la atención y minimizar las distracciones. La sensibilidad a las distracciones está considerablemente influenciada por la resistencia a la incomodidad, tareas dispersas e incómodas o de dificultad superior a las capacidades de los empleados provocarán distracción. En un nivel 
práctico es necesario establecer un tiempo para reflexión, para abordar las tareas más desafiantes y definir prioridades. Todo esto requiere una cantidad considerable de energía.

Una autonomía responsable puede convertirse en el método más eficaz para mejorar y mantener la productividad, aunque una implementación deficiente de este método puede resultar en distracción y tiempos más largos de entrega de tareas. Casi todas las personas se concentran mejor cuando obtienen la libertad de decidir cuándo y cómo trabajaran además de hacerse responsables por el valor que producen.

\section{Conclusiones}

Identificar las cuatro áreas de necesidades básicas de los colaboradores de una empresa resulta esencial para que los líderes puedan motivar acorde cada situación, nutrir la sostenibilidad, la seguridad, la manifestación de la propia personalidad y la trascendencia de manera constante aumenta la productividad de los empleados y favorece a las relaciones organizacionales brindando a la empresa un ambiente óptimo para desarrollar sus actividades. Preferir los resultados de valor en lugar de los resultados de tiempo conviene más a los intereses económicos de una compañía y a los intereses de desarrollo humano de los empleados.

Schwartz, Gomes y McCarthy describen la forma en que las empresas líderes promueven en los trabajadores la creatividad, la salud física y mental y dan un importante puesto al descanso con la intención de aumentar el rendimiento derivado de las recargas de energía. La productividad de una empresa no se ve reflejada en el número de horas que los empleados laboran sino en la eficacia del trabajo que realizan.

\section{Referencias}

[1] Schwartz, T., Gomes, J., \& McCarthy, C. (2013). La anti-productividad. $1^{\mathrm{a}}$ ed. Buenos Aires: Granica 